\title{
Research on the Influence of Cognitive and Metacognitive Strategies on English Listening Training
}

\author{
HUA Min \\ School of Foreign Languages, \\ Wuhan Textile University \\ Wuhan, China \\ E-mail: Rebecca_huamin@126.com
}

Keywords: SLA theory; language input; Cognitive and metacognitive strategies; SBI

\begin{abstract}
Bases on cognitive strategy and metacognitive strategy theory and Strategy-based Instruction (SBI), the study has adopted a descriptive design with quantitative data gathering and analyzing methods to investigate the use of cognitive and metacognitive strategies and to study and illustrate the importance of listening strategies in improving listening and show how effective metacognitive and cognitive strategies-based instruction in improving college English listening. The major contribution of the study is its demonstration of the effectiveness of SBI for college students' English listening proficiency and strategy use.
\end{abstract}

\section{Introduction}

According to second language acquisition (SLA) theory, language input is the basic necessity in language acquisition and listening has taken a great part in the language input. Meanwhile, according to previous scholars' researches, strategies play an important role in the learning process. [1] O' Malley and Chamot (2001) hold the view that cognitive strategies may be restricted to be applied to specific type of task during the learning process such as listening and reading comprehension, but metacognitive strategies can be applied to more kinds of learning tasks. [2] Skehan (1998) and Zheng Ming (2000) stress the importance of metacognitive strategies for example, O' Malley and Chamot (2001:8) indicate that if learners lack of appropriate metacognitive approaches, they will be essentially losing directions or chances to make their learning plans, monitor their progress, or recheck their outcomes and results and further learning directions. [3] Skehan (1998:265) holds the opinion that metacognitive strategies apply in a broader area than cognitive strategies and possibly indeed subsume and surpass them. According to previous scholars' researches, strategies play an important role in the learning process. Therefore, this thesis aims to study and illustrate the importance of listening strategies in improving listening and show how effective metacognitive and cognitive strategies-based instruction in improving college English listening. In addition, this thesis also copes with the study on ways to apply strategies instruction to college students' listening classroom.

\section{Methodolody}

\section{Research questions}

This study aims to answer the following four research questions:

1. What are the effects of metacognitive and cognitive strategies-based instruction on learners' English listening proficiency?

2. What are the impacts of metacognitive and cognitive strategies-based instruction on learners' strategy employment situation? 


\section{Research Subject}

The subjects participating in the present study are 80 second-year undergraduate students at Wuhan Textile University. One class of 40 students comprised Experiment Group (EG) which received the combing training of cognitive and metacognitive strategies in listening classroom teaching. Another class of 40 comprised Comparison Group (CG), receiving only cognitive strategies training. As they have been very familiar with the college English and have high desire to pass the CET-4, they have great interest in learning the strategies.

\section{Research Instruments}

The instruments employed include a questionnaire and two English proficiency tests: pre-test and post-test. The questionnaire was used for collecting information on learners' listening awareness, listening metacognitive and cognitive strategies use. [4] The questionnaire was given to the two groups at the beginning of the new semester on August 29, 2013 at the same time.

\section{Data Collection}

These data were from the process of analyzing the students' scores by computer software SPSS17.0. Paired Sample T-Test was used to make analysis of the intra-group difference and we use descriptive statistics to make the description of the inter-group difference respectively.

\section{Results and Discussion}

Research Question 1: The effects of metacognitive and cognitive strategies-based instruction on learners' English listening proficiency.

In order to establish the homogeneity of the two groups of listening, an independent-sample t-test was to examine the difference among the performance of the two groups on the listening proficiency test before the training.

TABLE 1 Listening PROFICIENCY PRE-TEST BETWEEN EG AND CG By INDEPENDENT SAMPLES TEST

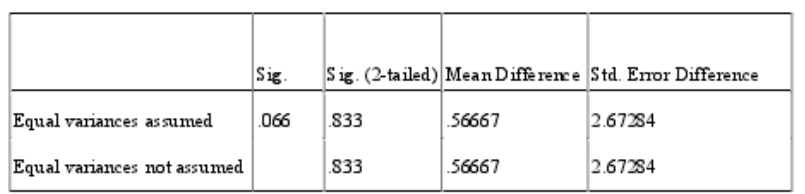

According to table 1 , the first sig. is $0.066(>0.05)$ that means the statistics is log-normally distributed and can be analyzed by independent sample test. The second Sig. (2-tailed)=0.833 ( $>0.05$ ) means there is not any significant difference between the two groups and they can be seen as parallel in the listening proficiency.

TABLE 2 MEANS OF PRE-TEST AND POST-TEST OF EG FOR LISTENING PROFICIENCY

\begin{tabular}{lcc}
\hline Class & N & Mean \\
\hline Pre-test & 30 & 24.0667 \\
Pro-test & 30 & 36.7000 \\
\hline
\end{tabular}

As it is stated in Table 2 the mean of post-test in EG(36.7000) is about 12 points higher than that of the pre-test (24.0667) which means the combing training of cognitive and metacognitive strategies is very effective in terms of listening proficiency.

TABLE 3 MEANS OF PRE-TEST AND POST-TEST OF CG FOR LISTENING PROFICIENCY

\begin{tabular}{lll}
\hline Class & N & Mean \\
\hline Pre-test & 30 & 23.5000 \\
Pro-test & 30 & 28.6667 \\
\hline
\end{tabular}


Table 3 is about the means of pre-test and post-test of CG for listening proficiency, the mean of post-test is also higher than that of the pre-test which indicates that the training of cognitive strategies is also helpful in improving listeners' listening proficiency.

\section{TABLE 4 COMPARISON BETWEEN EG AND CG' S PRE-TEST AND POST-TEST OF LISTENING PROFICIENCY} BY PAIRED-SAMPLES T-TESTS

\begin{tabular}{|l|l|l|l|}
\hline & \multicolumn{1}{|c|}{ Pair } & \multicolumn{1}{|c|}{ Mean } & \multicolumn{1}{c|}{ Sig. (2-tailed) } \\
\hline 1 & Pre-test-EG - post-test-EG & -12.63333 & .000 \\
\hline 2 & Pre-test-CG - post-test-CG & -5.16667 & 047 \\
\hline
\end{tabular}

Table 4 is about the paired-samples T-tests between two pairs, one of which is between the results of pre-test and post-test of EG, the other is between results of pre-test and post-test of CG. The Sig.(2-tailed) of the first pair is $.000(<0.01)$ that means there is very significant difference between the results of pre-test and post-test of EG. And the Sig.(2-tailed) of the first pair is .047 $(<0.05)$ that means there is significant difference between the results of pre-test and post-test of CG. That is to say, both kinds of training do have effects.

Research Question 2: The impacts of metacognitive and cognitive strategies-based instruction on learners' strategy employment situation.

There are 5 scores: 1, 2, 3, 4, 5.1 means totally disagree, 2 means almost disagree, 3 means partially agree, 4 means almost agree and 5 means totally agree. The higher the score, the more we can know that the learner has mastered the specific strategy.

TABLE 5 COMPARISON OF EG AND CG'S PRE-TRAINING OF COGNITIVE STRATEGIES BY PAIRED-SAMPLES T-TESTS

\begin{tabular}{|c|c|c|c|c|}
\hline & Pair & Mean & S tandard deviation & S ig. (2-tailed) \\
\hline 1 & Pre-EG-cl - pre-CG-cl & .50000 & 1.35524 & .053 \\
\hline 2 & Pre-EG-c2 - pre-CG-c2 & -.23333 & 1.27802 & .326 \\
\hline 3 & Pre-EG-c3 - pre-CG-c3 & .63333 & 1.71169 & .052 \\
\hline 4 & Pre-EG-c4 - pre-CG-c4 & .10000 & 1.60495 & .735 \\
\hline 5 & Pre-EG-c5 - pre-CG-c5 & .20000 & 1.60602 & .501 \\
\hline 6 & Pre-EG-c6 - pre-CG-c6 & -.13333 & 1.35782 & .595 \\
\hline 7 & Pre-EG-c7 - pre-CG-c7 & .26667 & 1.22990 & .245 \\
\hline 8 & pre-EG-c5 - pre-CG-cS & .00000 & 1.14470 & 1.000 \\
\hline 9 & Pre-EG-c9 - pre-CG-c9 & .36667 & 1.06620 & .070 \\
\hline 10 & preEGc10 - preCGc10 & .30000 & 1.23596 & .194 \\
\hline 11 & Pre-EG-c11 - pre-CG-cl1 & .40000 & 1.27577 & .097 \\
\hline 12 & Pre-EG-c12 - pre-CG-c12 & .10000 & 1.21343 & .655 \\
\hline 13 & Pre-EG-c13 - pre-CG -c13 & .43333 & 1.16511 & .051 \\
\hline 14 & Pre-EG-c14 - pre-CG-c14 & .16667 & 1.41624 & .524 \\
\hline 15 & Pre-EG-c15 - pre-CG-c15 & -.03333 & 1.42595 & .899 \\
\hline
\end{tabular}

According to Table 5, the paired-samples T-tests of comparison of EG's pre-training of cognitive strategies prove that there is no significant difference (all the sig.(2-tailed) $>0.05$ ) existed in cognitive strategies and metacognitive strategies between both groups. 
TABLE 6 EG'S PRE- AND POST- TEST FOR COGNITIVE STRATEGIES BY PAIRED-SAMPLES T-TESTS

\begin{tabular}{|c|c|c|c|c|}
\hline & Pair & Mean & Standard deviation & S ig. (2-tailed) \\
\hline 1 & preEGc1 - postEGc1 & -.13333 & 1.67607 & .666 \\
\hline 2 & preEGc2 - postEGc2 & -.50000 & 1.22474 & .033 \\
\hline 3 & preEGc3 - postEGc3 & -.36667 & .92786 & .039 \\
\hline 4 & preEGc4 - postEGc4 & -.36667 & 1.21721 & .110 \\
\hline 5 & preEGc5 - postEGc5 & -.13333 & 1.40770 & .608 \\
\hline 6 & preEGc6 - postEGc6 & -.76667 & 1.30472 & .003 \\
\hline 7 & preEGc7 - postEGc7 & -.36667 & 1.15917 & .094 \\
\hline 8 & preEGc8 - postEGc8 & -.43333 & 1.10433 & .040 \\
\hline 9 & preEGc9 - postEGc9 & -.23333 & 1.65432 & .446 \\
\hline 10 & preEGc10 - postEGc10 & -.33333 & 1.12444 & .115 \\
\hline 11 & preEGc11 - postEGc11 & .00000 & 1.1447 & 1.000 \\
\hline 12 & preEGc12 - postEGc12 & -.53333 & 1.13664 & .016 \\
\hline 13 & preEGc13 - postEGc13 & -.26667 & 1.33735 & .284 \\
\hline 14 & preEGc14 - postEGc14 & -.26667 & 1.20153 & .234 \\
\hline 15 & preEGc15 - postEGc15 & -.23333 & 1.10433 & .257 \\
\hline
\end{tabular}

As it is indicated in Table 6, it is easy to find that all the mean of post-EG about cognitive strategies surpass that of pre-EG because all the mean of preEGc1 - postEGc1 are negative. In the mean time, it is mentioned that only five pairs of items present significant difference $(p<0.05)$. The five items are about vocabulary, meaning-seeking, note-taking, visual-image, inferring.

TABLE 7 CG' S PRE- AND POST- TEST FOR COGNITIVE STRATEGIES BY PAIRED-SAMPLES T-TESTS

\begin{tabular}{|c|c|c|c|c|}
\hline & Pair & Mean & Standard de viation & Sig. (2-tailed) \\
\hline 1 & preCGcl - postCGcl & -80000 & 1.37465 & .003 \\
\hline 2 & preCGc2 - postCGc2 & -.50000 & 1.27982 & .041 \\
\hline 3 & preCGc3 - postCGc3 & -.83333 & 1.34121 & .002 \\
\hline 4 & preCGc4 - postCGc4 & -.50000 & 1.45626 & .070 \\
\hline 5 & preCGc5 - postCGc5 & -23333 & 1.16511 & .282 \\
\hline 6 & preCGc6 - postCGc6 & -.26667 & $1.0 \$ 066$ & .187 \\
\hline 7 & preCGc7 - postCGc7 & -.7000 & 1.17884 & .003 \\
\hline$s$ & preCGcS - postCGcS & -26667 & 1.43679 & .315 \\
\hline 9 & preCGc9-postCGc9 & -96667 & 1.32570 & .000 \\
\hline 10 & preCGc10 - pos tCGc10 & -.36667 & 1.21721 & .110 \\
\hline 11 & preCGcll - postCGc1l & -.40000 & 1.30252 & .103 \\
\hline 12 & preCGc12- postCGc12 & -26667 & $1.0 \$ 666$ & .187 \\
\hline 13 & preCGc13 - pos tCGc13 & -.46667 & .97320 & .014 \\
\hline 14 & preCGc14 - postCGc14 & -33333 & 1.09334 & .106 \\
\hline 15 & preCGc15 - postCGc15 & -.06667 & 1.17248 & .758 \\
\hline
\end{tabular}

As it is indicated in Table 7, all the mean of post-CG about cognitive strategies surpass that of pre-CG, which indicates that the cognitive strategies training in both classes have improved learners' cognitive strategies employment situation. And six pairs of items experience significant difference $(\mathrm{p}<0.05)$ which are vocabulary, meaning-seeking, visual image and grammar. Other items in both T-tests present no significant difference. 
TABle 8 Comparison of EG and CG's Pre-Training of MEtacognitive Strategies by PAIRED-SAMPLES T-TESTS

\begin{tabular}{|c|c|c|c|c|}
\hline & Pair & Mean & Stanlard deviation & Sig. (2-tailed) \\
\hline 1 & Pre-EG-b1 - pre-CG-b1 & -.26667 & 1.43679 & .318 \\
\hline 2 & Pre-EG-b2 - pre-CG-b2 & -.43333 & 1.30472 & .079 \\
\hline 3 & Pre-EG-b3 - pre-CG-b3 & -36667 & 1.44993 & .177 \\
\hline 4 & Pre-EG-b4 - pre-CG-b4 & -.06667 & 2.09981 & .863 \\
\hline 5 & Pre-EG-b5 - pre-CG-b 5 & -.43333 & 1.19434 & .056 \\
\hline 6 & Pre-EG-b6 - pre-CG-b6 & -.43333 & 1.25075 & .068 \\
\hline 7 & Pre-EG-b 7 - pre-CG-b 7 & .10000 & 1.80707 & .764 \\
\hline$s$ & Pre-EG-bS - pre-CG-bS & -.16667 & 1.78274 & .612 \\
\hline 9 & Pre-EG-b9 - pre-CG-b9 & -.40000 & 1.24845 & .090 \\
\hline 10 & Pre-EG-b 10-pre-CG-b10 & .23333 & 1.13512 & .269 \\
\hline 11 & Pre-EG b11-pre-CG-b 11 & -.40000 & 1.32873 & .110 \\
\hline 12 & Pre-EG-b12-pre-CG-b12 & -53333 & 1.61316 & .081 \\
\hline
\end{tabular}

As it is mentioned in Table 8, there is no significant difference between CG and EG's metacognitive strategies before the training (Sig. (2-tailed) $>0.05$ ).

TABLE 9 EG'S PRE- AND POST- TEST FOR METACOGNITIVE STRATEGIES BY PAIRED-SAMPLES T-TESTS

\begin{tabular}{|c|c|c|c|}
\hline Pair & Mean & Standard deviation & Sig. (2-tailed) \\
\hline preEGb l - postEGb l & -1.43333 & 97143 & .000 \\
\hline pie EGb 2 - postEGb 2 & -1.30000 & 1.11880 & .000 \\
\hline pie EGb 3 - pos tEGb 3 & -.86667 & 1.27937 & .001 \\
\hline pre EGb4 - pos tEGb4 & -.96667 & 1.37674 & .001 \\
\hline preEGb 5 - pos $\mathrm{EEGb} 5$ & -1.30000 & 1.02217 & .000 \\
\hline pie EGb 6 - pos $\mathrm{tEG} 66$ & -1.06667 & 1.20153 & .000 \\
\hline pre EGb 7 - pos $\mathrm{EEGb} 7$ & -.56667 & 1.35655 & .030 \\
\hline preEGbS - pos tEGbS & -.90000 & 1.24152 & .000 \\
\hline pie EGb9 - postEGb9 & -1.03333 & S5029 & .000 \\
\hline pre EGb 10 - postEGb 10 & -1.20000 & 99655 & .000 \\
\hline preEGb 11 - postEGbll & -.90000 & 1.21343 & .000 \\
\hline pre EGb 12 - postEGb 12 & -.86667 & 93710 & .000 \\
\hline
\end{tabular}

And from the following Table 9 it is easy to find that all the mean of post-EG about metacognitive strategies surpass that of pre-EG (the mean of Pre-EG - pre-CG are negative). And all the items of post-EG's metacognitive strategies presents significant difference (Sig. (2-tailed) $<0.01$ ). These data indicate that the metacognitive strategies training in EG has greatly improved learners' metacognitive strategies employment situation. It is evident that SBI training exerted a significant effect on learners' use of metacognitive strategies in listening learning.

\section{Conclusion}

The present study proves that listening strategies training has positive impact on learners' listening proficiency and listening strategies employment situation. Research on cognitive and metacognitve strategies-based instruction in college English learners is a worthy attempt to conduct. Despite the disadvantage of the study, this study provides insights into college students English listening strategies employment and instruction. There is no doubt that more strategies and further researches are needed as a supplement to this study, and especially to pursue the empirical study of strategies-based instruction which is concentrated on improving listening ability. 


\section{References}

[1] Rost, M. Teaching and Researching Listening [M]. Beijing: Foreign Language Teaching and Research Press. 2005.

[2] Wu Weiying. Using Learning Strategies to Develop Listening Comprehension — A Case Study [J]. Teaching English in China. 2000(1):36-41.

[3] Vandergrift, L. Facilitating Second Language Listening Comprehension: Acquiring Successful Strategies [J]. ELT Journal. 1999(3): 168-176.

[4] Skehan, P. A Cognitive Approach to Language Learning [M]. Shanghai: Shanghai Foreign Language Education Press.1998.

[5] Arnett,JJ.Emerging adulthood: A theory of development from the late teens through the twenties. American Psychologist. 2000 